\title{
Genetic Engineering of an Artificial Metalloenzyme for Transfer Hydrogenation of a Self-Immolative Substrate in E. coli' $s$ Periplasm
}

\author{
Jingming Zhao, Johannes G. Rebelein, Hendrik Mallin, Christian Trindler, Michela M. Pellizzoni and \\ Thomas R. Ward*
}

Department of Chemistry, University of Basel, Mattenstrasse 24a, BPR 1096, CH-4058 Basel, Switzerland

Supporting Information Placeholder

\begin{abstract}
Artificial metalloenzymes (ArMs), which combine an abiotic metal cofactor with a protein scaffold, catalyze various synthetically useful transformations. To complement the natural enzymes' repertoire, effective optimization protocols to improve ArM's performance are required. Here we report on our efforts to optimize the activity of an artificial transfer hydrogenase (ATHase) using E. coli whole cells. For this purpose, we rely on a self-immolative quinolinium substrate which, upon reduction, releases fluorescent umbelliferone, thus allowing efficient screening. Introduction of a loop in the immediate proximity of the Ircofactor afforded an ArM with up to fivefold increase in transfer hydrogenation activity compared to the wild-type ATHase using purified mutants.
\end{abstract}

Enzyme engineering is a powerful means to optimize performance of proteins. ${ }^{1-5}$ Both natural and artificial enzymes have been engineered to catalyze a variety of new-to-nature reactions. ${ }^{6-}$ ${ }^{15}$ Artificial metalloenzymes (ArMs) result from the introduction of an abiotic metallocofactor within a protein scaffold. In this context, hemoproteins ${ }^{16-18}$ streptavidin (Sav hereafter), ${ }^{7,19}$ and $P f u$ prolyl-oligopeptidase ${ }^{11,12}$ have proven versatile. The most active ArM reported rely on precious metal cofactors, which are frequently poisoned by of thiols. ${ }^{20-23}$ Critical analysis of a typical workflow for the directed evolution of ArMs reveals the following bottlenecks: $i$ ) Need to perform catalysis using (partially) purified protein samples. Such samples lack a phenotype-genotype linkage, which is critical in high throughput campaigns ii) Extraction and HPLC analysis is often time-consuming.

We report our efforts to address both challenges by i) compartmentalizing an artificial transfer-hydrogenase (ATHase hereafter) in the periplasm of $E$. coli, thus allowing to maintain the phenotype-genotype linkage and $i$ ) relying on a self-immolative substrate that releases a fluorophore upon reduction of its iminium moiety. In a related context, Lo and coworkers reported on a bodipy-flanked aldehyde which, upon reduction by an Irpianostool in mammalian cells, leads to the generation of a fluorescent signal. ${ }^{24}$

Self-immolative substrates consist of a cap, a self-immolative core and a leaving group, Figure 1a. ${ }^{25,26}$ Self-immolative substrates have found wide applications in bioanalysis, ${ }^{27}$ prodrugs, ${ }^{28,29}$ high-throughput screening or biomolecular imaging ${ }^{30}$ etc. We hypothesized that a quinolinium substrate, which upon $\mathrm{N}=\mathrm{C}$

reduction, may undergo self-immolation to release a fluorophore via the formation of iminoquinone-methide intermediate $3{ }^{31}$ Figure $1 \mathrm{~b}$. The resulting electrophilic intermediate 3 reacts with nucleophiles in solution (either water or nucleophilic aminoacid residues present on the surface of the protein). ${ }^{32}$

(a) Self-immolative substrate
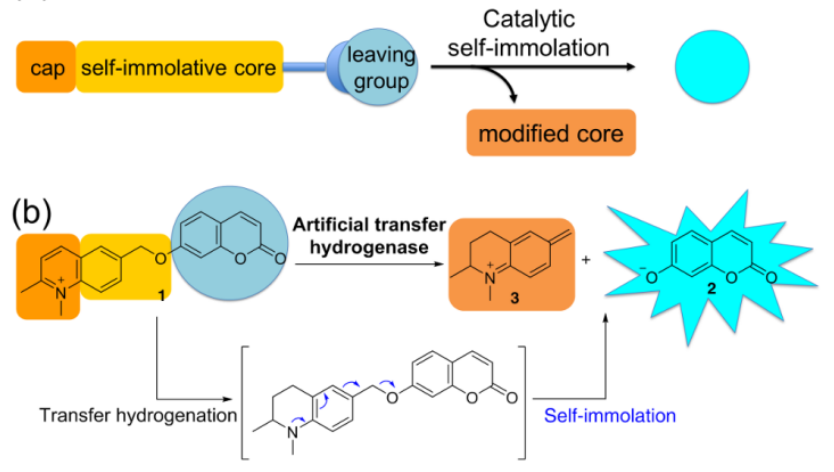

Figure 1. (a) Self-immolative substrate. (b) Reduction of the quinolinium moiety in substrate $\mathbf{1}$ leads to the release of umbelliferone $\mathbf{2}$ which can be detected by fluorescence.

We selected the biotin-streptavidin couple to ensure localization of the Ir-based ATHase cofactor. ${ }^{33-38}$ Analysis of the various $\mathrm{X}$-ray structures of $\left[\mathrm{Cp} * \operatorname{Ir}\left(\right.\right.$ biot- $p$-L)Cl] $\mathrm{Sav},{ }^{39,40}$ reveals that the cofactor, located in the biotin-binding vestibule, is solvent exposed. Introduction of additional structural elements around the biotin-binding vestibule may have a significant impact on the catalytic performance. ${ }^{41}$ Thanks to its stability and plasticity, we have shown that Sav is remarkably tolerant towards the modification of its loops. ${ }^{42}$ Having reported that mutations within the 7,8loop (i.e. between residues 112 and 124, especially positions S112 and K121) significantly affect catalytic performance of various ArMs based on the biotin-streptavidin technology, ${ }^{43,44}$ we selected a 24-residue helix-turn-helix motif designed by the Baker group $^{45,46}$ (FPD, Figure 2a), and inserted it between residues 115 and 117 of Sav, Figure 2. We hypothesized that the insertion of a motif in the proximity of the metal cofactor may significantly influence the catalytic performance of the ArM. The FPD-chimera could be expressed in E. coli and purified by affinity chromatography on an iminobiotin-sepharose matrix, highlighting its biotinbinding affinity (See SI Figure S2 for details). To circumvent 
poisoning of the precious metal cofactor by glutathione, ${ }^{47,48}$ we secreted the Sav-FPD chimera to the periplasm by fusing it with the OmpA $N$-terminal signal peptide. SDS-PAGE analysis of $E$. coli cells containing the OmpA-Sav-FPD construct confirmed localization of the soluble biotin-binding protein within its periplasm (Figure S1). As E. coli's periplasm contains significantly lower glutathione concentrations than the cytoplasm, ${ }^{49}$ and the equilibrium lies mostly to the oxidized disulfide form, we anticipated that $\left[\mathrm{Cp}^{*} \operatorname{Ir}(\right.$ biot- $p$-L)Cl] Sav-FPD would maintain its ATHase activity in the periplasm, as we have recently demonstrated for metathesis using a biotinylated Ru-cofactor. ${ }^{47}$

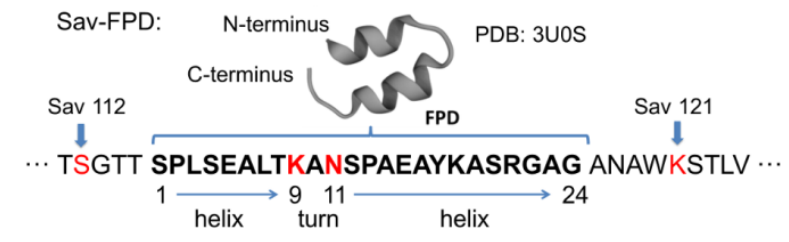

Figure 2. Introduction of an additional structural motif around the biotin-binding vestibule may influence the ATHase activity. (a) Sav-FPD chimera containing a cartoon representation of the FPD loop (in grey) and its sequence (in bold); residues highlighted in red were subjected to "saturation" mutagenesis.

Five constructs were tested for the initial periplasmic screening: empty vector (as negative control), Sav WT, Sav-FPD, Sav K121A and Sav-FPD K121A. Following E. coli culture, the cells were incubated with the buffer containing $\left[\mathrm{Cp}^{*} \operatorname{Ir}(\right.$ biot- $\left.p-\mathrm{L}) \mathrm{Cl}\right]$ and washed to remove the unbound cofactor (See SI for details). The cell pellet was resuspended in a solution containing formate $(1 \mathrm{M})$ and substrate $1(1 \mathrm{mM})$. Limited conversion (i.e. $<4 \%)$ could be detected after 16 hours at $25{ }^{\circ} \mathrm{C}$, either by fluorescence $(322 \mathrm{~nm}$ excitation, $440 \mathrm{~nm}$ readout) or by UPLC-MS. Speculating that the low concentrations of glutathione present in the periplasm may suffice to irreversibly poison $[\mathrm{Cp} * \operatorname{Ir}($ biot $-p-\mathrm{L}) \mathrm{Cl}]$, we added diamide $(2 \mathrm{mM})$ to fully oxidize glutathione. ${ }^{21,50}$ Again here, no conversion could be observed. Inspired by the $\mathrm{Cu}(\mathrm{II})$-catalyzed glutathione oxidation, ${ }^{51,52}$ we washed the $E$. coli cells with [Cu(gly) 2$]$ ( $2 \mathrm{mM}$ in MOPS buffer). To our delight, the uncaging of umbelliferone 2 was observed when this protocol was applied. Increasing the $[\mathrm{Cp} * \operatorname{Ir}($ biot $-p-\mathrm{L}) \mathrm{Cl}]$ cofactor concentration from 1 $\mu \mathrm{M}$ to $5 \mu \mathrm{M}$ led to an increase in yield (Figure $3 \mathrm{~b}$ ). Thanks to the good Sav-FPD expression levels in E. coli's periplasm, and the sensitivity of the fluorescence-based monitoring of catalysis, the entire screening procedure could be carried out in a 96-well plate format, Figure 4c.
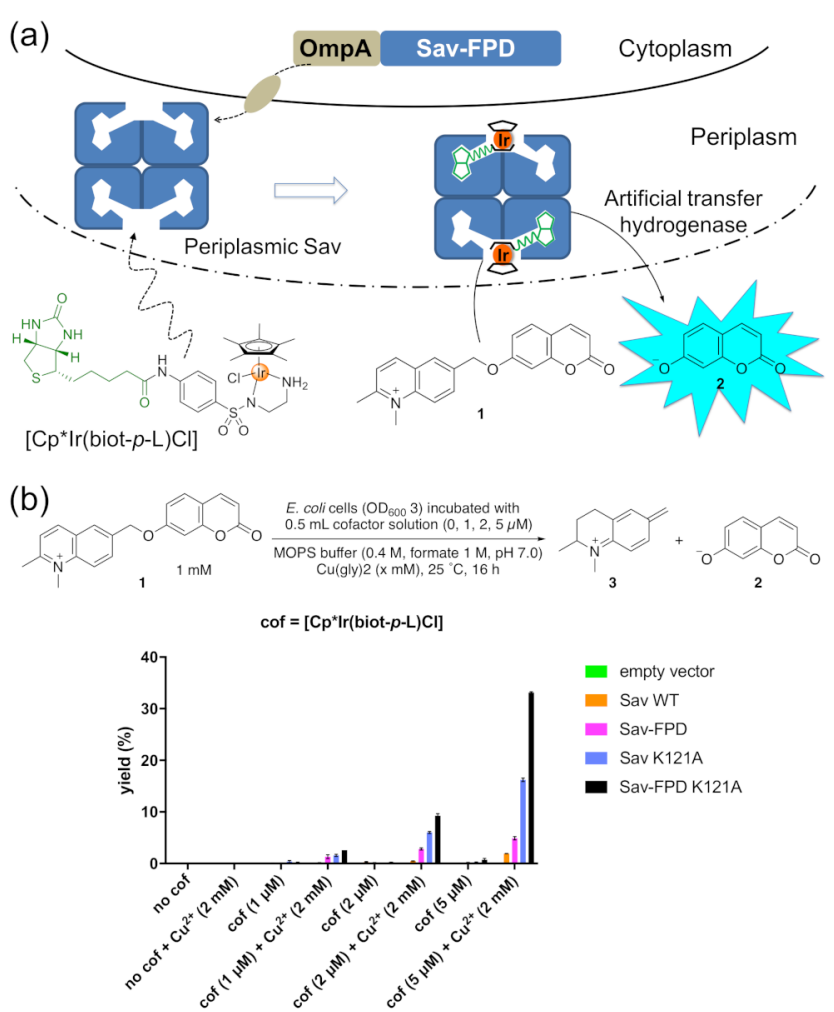

Figure 3. Assembling and screening ATHase in E. coli whole cells. (a) Localization of Sav-FPD chimeras within the periplasm of $E$. coli allows to screen whole cells for ATHase activity using the self-immolative quinolinium substrate 1. (b) Addition of $\left[\mathrm{Cu}(\mathrm{gly})_{2}\right]$ significantly improves ATHase activity in E. coli. Bars show the mean of two independent replicate cultures with error bars indicating one standard deviation (See Table S10 for details).

Past experience with [Cp* $\operatorname{Ir}($ biot $-p-\mathrm{L}) \mathrm{Cl}] \quad$ Sav highlighted the detrimental influence of K121 on ATHase activity. ${ }^{23,53}$ We hypothesized that this residue may also affect catalytic activity of $[\mathrm{Cp} * \operatorname{Ir}($ biot- $p-\mathrm{L}) \mathrm{Cl}] \quad$ Sav-FPD. Gratifyingly, the catalytic performance of [Cp* $\operatorname{Ir}($ biot- $p$-L)Cl] Sav-FPD K121A was markedly improved compared to [Cp* $\operatorname{Ir}($ biot- $p$-L)Cl] Sav-FPD and Sav $\mathrm{K} 121 \mathrm{~A}$ upon addition of $5 \mu \mathrm{M}$ cofactor and $2 \mathrm{mM}\left[\mathrm{Cu}(\mathrm{gly})_{2}\right]$, (33\% yield and 5\% yield for the Sav-FPD K121A and Sav-FPDATHase respectively after 16 hours), Figure $3 \mathrm{~b}$. To determine the turnover numbers (TONs) of the ArMs within E. coli whole cells, these were subjected to ICP-MS analysis following the cell culture, incubation with the cofactor and washing (See SI for details). The following results were obtained: empty plasmid $(0.15 \mathrm{nmol}$ Ir, thus corresponding to 1 TON), Sav WT (0.36 nmol Ir, 11 TON), Sav K121A (0.33 nmol Ir, 98 TON) and Sav-FPD K121A (0.48 nmol Ir, 137 TON) (Table S11).

Next, we set out to optimize the catalytic activity by directed evolution relying on a 96 well plate assay. We built a mutant library relying on the NHT codons (that encode the A, N, D, H, I, L, F, P, S, T, Y and V amino acids) for mutations at the following positions: S112, K121, FPD(K9) and $\operatorname{FPD}(\mathrm{N} 11)$, Figure 2. The NHT primers code mostly for hydrophobic residues, which are known to positively influence the performance of ArMs. ${ }^{43,44}$

In order to ensure full coverage at positions S112 and K121 (i.e. $1212=144$ mutants), we mutated simultaneously both positions. Accordingly, 450 clones were screened and the best hits were sequenced. Eight independent biological replicates were tested revealing that Sav-FPD S112A-K121P performs best, followed by the Sav-FPD S112V-K121A. The low isolated yield resulting from the cytoplasmic expression of Sav-FPD S112A- 
K121P led us to select the better-behaved Sav-FPD S112V$\mathrm{K} 121 \mathrm{~A}$ as template for the next generation for FPD-centered mutagenesis. The positions $\mathrm{K} 9$ and N11, which are part of the FPD loop, were randomized sequentially using NHT codons. None of the triple or quadruple mutants screened outperformed [Cp*Ir(biot- $p$-L)Cl] Sav-FPD S112V-K121A for the reduction of the quinolinium substrate 1 after screening 600 clones, Figure 4.

Next, Sav-FPD S112V-K121A was cocrystallized with [Cp*Ir(biot- $p-\mathrm{L}) \mathrm{Cl}]$ (See SI for details). The structure was solved by molecular replacement. Comparison with the structure of [Cp*Ir(biot-p-L)Cl] Sav S112A (PDB: 3PK2) reveals a shift of the 4,5 -loop by $5.6 \AA$ and a change in directionality of the 7,8 loop, pointing towards the cofactor, Figure 5. The conformation of the 4,5-loop is stabilized through formation of ten new hydrogen bonds (Figure S4). The FPD-fragment could not be built due to insufficient electron density, presumably caused by its flexibility. The increased $\left[\mathrm{Cp}^{*} \operatorname{Ir}(\right.$ biot- $\left.p-\mathrm{L}) \mathrm{Cl}\right]$ occupancy (i.e. $80 \%$, compared to $50 \%$ for related structures) ${ }^{39}$ suggests that the FPD-loop shields the biotin-binding vestibule and contributes to localize the cofactor. The proximity of two neighboring cofactors (Ir $\mathrm{Ir}=$ $5.3 \AA$ in Sav monomers $b$ and $d$ in Figure 5) highlights the presence of a bridging chloride.

(a)

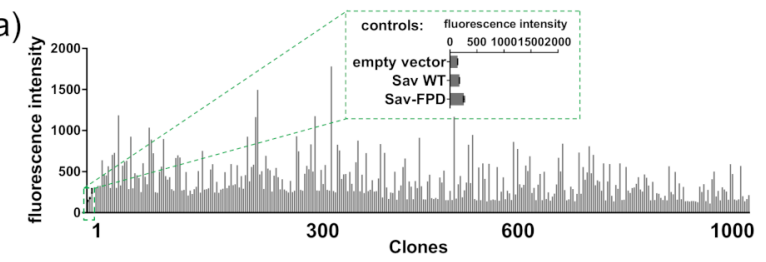

(b)

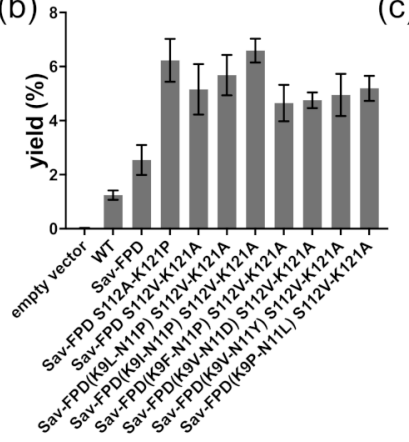

(c)

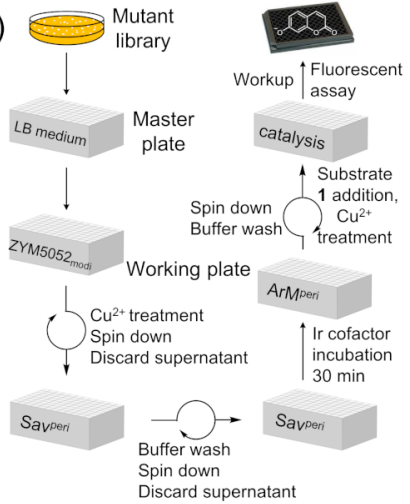

Figure 4. Directed evolution of ATHase using the quinolinium substrate 1. (a) Screening results for "saturation" mutagenesis at positions S112, K121, FPD(K9) and FPD (N11) using NHT codons. (b) 8-replicate comparison for the most promising mutants. (c) protocol applied for the genetic optimization in a 96-well plate format.

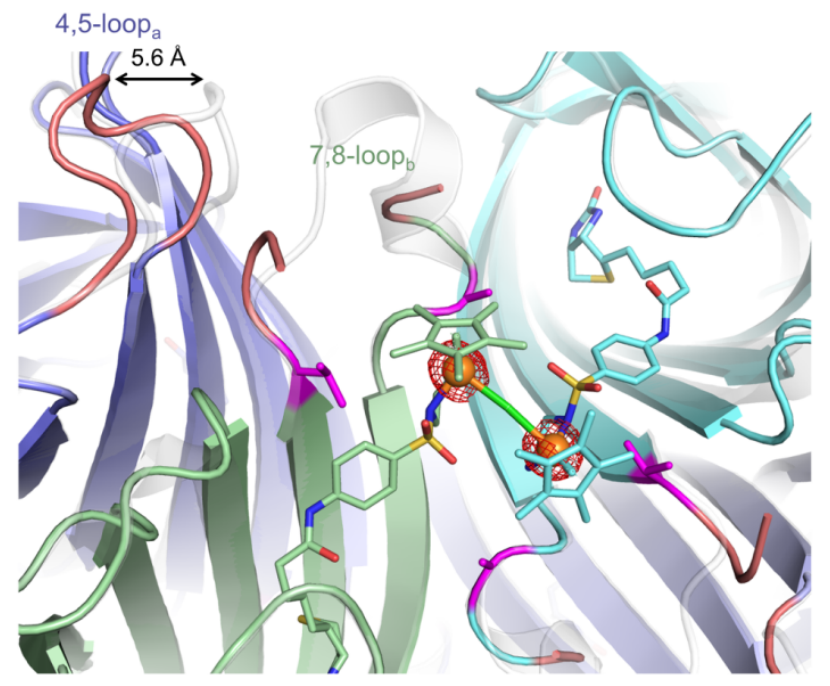

Figure 5. Overlay of the X-ray crystal structure of $\left[\mathrm{Cp}^{*} \operatorname{Ir}(\right.$ biot- $p$ L)Cl] Sav-FPD S112V-K121A (PDB: 6GMI) with [Cp*Ir(biot$p$-L)Cl] Sav S112A (PDB: 3PK2). The protein is depicted as cartoon representation (monomer a of Sav-FPD S112V-K121A in blue, monomer $\mathrm{b}$ in green, monomer $\mathrm{c}$ in lilac and monomer $\mathrm{d}$ in cyan; Sav S112A in grey), the mutated residues S112V-K121A are depicted as magenta sticks. The bound [Cp* $\operatorname{Ir}($ biot- $p-\mathrm{L}) \mathrm{Cl}]$ cofactor is displayed as stick with the iridium as orange sphere (anomalous electron density: red mesh at $3 \sigma$ ); chloride, green; sulfur, yellow; nitrogen, blue; oxygen, red. Structural features deviating from PDB 3PK2 are highlighted in pale red. The FPDfragment could not be fully resolved.

The improved whole cell ATHase activity may result from a combination of two factors: $i$ ) improved activity of the Sav-FPD chimera and/or ii) higher protein expression level of the recombinant protein in the periplasm. Screening with purified Sav samples in vitro, allows to deconvolute both factors. The in vitro ATHase activity towards four imines $\mathbf{4 a}-\mathbf{7 a}$ and two quinoliniums 1 and 8a were tested. Results are summarized in Figure 6.

Screening using purified Sav-FPD samples with prochiral substrates 1 and 4a - 8a reveal several trends: i) Compared to Sav WT, introduction of the FPD structural motif (Sav-FPD) has a positive impact on the turnover numbers after 24 hours (TON). Up to a fivefold higher TON is observed in vitro for the salsolidine precursor 4a. ii) We suggest that the difference in trends for the in vivo vs. purified ATHase reflects different production levels of the various mutants in the periplasm. iii) Introduction of mutations at the base of loop 7,8 (i.e. Sav-FPD S112V-K121A) positively influences TON for three imine substrates: 5a, 6a, 7a and the quinolinium 1 and $\mathbf{8 a}$. iv) These mutations also significantly influence enantioselectivity, especially in for imine $\mathbf{4 a}$ and quinolinium 8a (See SI Table S8). It should be emphasized that the screening protocol focused on improving TON, not the enantioselectivity. v) Mutations within the FPD motif have ambivalent effects: while Sav-FPD(K9L-N11P) S112V-K121A leads to a significant decrease in TON for all substrates, the Sav-FPD(K9IN11P) S112V-K121A affords good TON in most cases. It is striking how this conservative K9L to K9I mutation affects the catalytic performance.

With the aim of developing a streamlined protocol for the directed evolution of ATHases using E. coli whole cells, we report four important findings. $i$ ) Asymmetric transfer hydrogenation using the $\left[\mathrm{Cp}^{*} \operatorname{Ir}(\right.$ biot- $p$ - $\left.\mathrm{L}) \mathrm{Cl}\right] \mathrm{Sav}$ ArM can be performed in the periplasm of $E$. coli. We hypothesize that this contributes to oxi- 
dize the glutathione present in the periplasm. ii) The introduction of a loop in the immediate proximity of the biotin-binding vestibule, combined with mutations within the 7,8-loop of Sav, has a positive effect on the performance of the engineered ATHase: up to $137 \mathrm{TON}$ in $E$. coli whole cells and up to fivefold improvement using purified ATHases. iii) The performance of the ATHase can be improved by directed evolution using $E$. coli whole cells. Upon relying on the self-immolative substrate $\mathbf{1}$, the screening protocol can be carried out in a 96 well plate format. $i v$ ) The trends in TON observed for the self-immolative substrate $\mathbf{1}$ are reflected in the TON of substrates $\mathbf{4 a}-\mathbf{8 a}$. Current efforts are aimed adapting this protocol to improve both the activity and the (pseudo)enantioselectivity of ATHase.

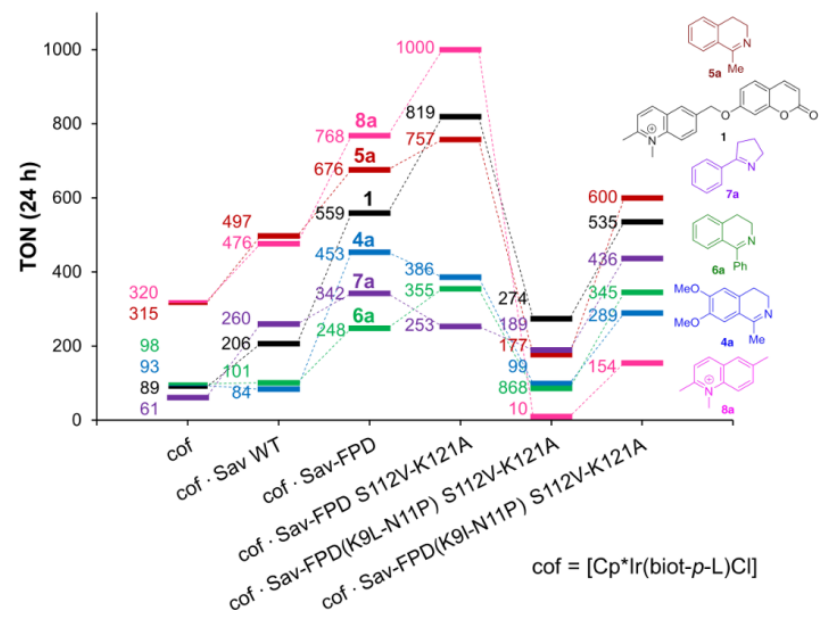

Figure 6. Substrate scope (TONs) for ATHase using mutants identified by self-immolative substrate 1 . (See Table S8 for ee).

\section{ASSOCIATED CONTENT}

Supporting Information is available free of charge on the ACS Publications website.

Experimental procedures, mutagenesis and screening protocols, crystallographic data and spectroscopic data (PDF)

\section{AUTHOR INFORMATION}

Corresponding Author

*thomas.ward@unibas.ch

ORCID:

Jingming Zhao: 0000-0001-7104-8990

Johannes G. Rebelein: 0000-0003-2560-716X

Michela M. Pellizzoni: 0000-0003-4294-0247

Thomas R. Ward: 0000-0001-8602-5468

Notes

The authors declare no competing financial interests.

\section{ACKNOWLEDGMENT}

TRW thanks the Swiss National Science Foundation (Grant SNF 200020_162348), the NCCR "Molecular Systems Engineering" and the ERC (the DrEAM) for generous support of this work. JZ thanks Chinese Scholarship Council and JR thanks the EMBO ALTF 194-2017 for scholarships respectively.

\section{REFERENCES}

(1) Chen, K.; Arnold, F. H. Proc. Natl. Acad. Sci. 1993, 90, 5618.

(2) Arnold, F. H. Angew. Chem., Int. Ed. 2018, 57, 4143.

(3) Turner, N. J. Nat. Chem. Biol. 2009, 5, 567.

(4) Reetz, M. T.; Zonta, A.; Schimossek, K.; Liebeton, K.; Jaeger, K. E. Angew. Chem., Int. Ed. 1997, 36, 2830.

(5) Wang, J.; Li, G.; Reetz, M. T. Chem. Commun. 2017, 53, 3916.

(6) Ilie, A.; Reetz, M. T. Isr. J. Chem. 2015, 55, 51.

(7) Schwizer, F.; Okamoto, Y.; Heinisch, T.; Gu, Y.; Pellizzoni, M. M.; Lebrun, V.; Reuter, R.; Köhler, V.; Lewis, J. C.; Ward, T. R. Chem. Rev. 2018, 118,142 .

(8) Ward, T. R. Angew. Chem., Int. Ed. 2016, 55, 14909

(9) Hyster, T. K.; Ward, T. R. Angew. Chem., Int. Ed. 2016, 55, 7344.

(10) Dydio, P.; Key, H. M.; Nazarenko, A.; Rha, J. Y.-E.; Seyedkazemi, V.; Clark, D. S.; Hartwig, J. F. Science 2016, 354, 102.

(11) Yang, H.; Swartz, A. M.; Park, H. J.; Srivastava, P.; EllisGuardiola, K.; Upp, D. M.; Lee, G.; Belsare, K.; Gu, Y.; Zhang, C.; Moellering, R. E.; Lewis, J. C. Nat. Chem. 2018, 10, 318.

(12) Srivastava, P.; Yang, H.; Ellis-Guardiola, K.; Lewis, J. C. Nat Commun. 2015, 6, 7789 .

(13) Obexer, R.; Godina, A.; Garrabou, X.; Mittl, P. R. E.; Baker, D.; Griffiths, A. D.; Hilvert, D. Nat. Chem. 2017, 9, 50.

(14) Song, W. J.; Yu, J.; Tezcan, F. A. J. Am. Chem. Soc. 2017, 139, 16772 .

(15) Song, W. J.; Tezcan, F. A. Science 2014, 346, 1525.

(16) Key, H. M.; Dydio, P.; Clark, D. S.; Hartwig, J. F. Nature 2016, $534,534$.

(17) Brandenberg, O. F.; Fasan, R.; Arnold, F. H. Curr. Opin. Biotechnol. 2017, 47, 102 .

(18) Bos, J.; Browne, W. R.; Driessen, A. J. M.; Roelfes, G. J. Am. Chem. Soc. 2015, 137, 9796.

(19) Wilson, M. E.; Whitesides, G. M. J. Am. Chem. Soc. 1978, 100, 306.

(20) Grimm, A. R.; Sauer, D. F.; Polen, T.; Zhu, L.; Hayashi, T.; Okuda, J.; Schwaneberg, U. ACS Catal. 2018, 8, 2611.

(21) Wilson, Y. M.; Dürrenberger, M.; Nogueira, E. S.; Ward, T. R. J. Am. Chem. Soc. 2014, 136, 8928.

(22) Hestericová, M.; Heinisch, T.; Alonso-Cotchico, L.; Maréchal, J. D.; Vidossich, P.; Ward, T. R. Angew. Chem., Int. Ed. 2018, 57, 1863.

(23) Mallin, H.; Hestericová, M.; Reuter, R.; Ward, T. R. Nat. Protoc. 2016, 11,835

(24) Bose, S.; Ngo, A. H.; Do, L. H.; J. Am. Chem. Soc. 2017, 139, 8792 .

(25) Alouane, A.; Labruère, R.; Le Saux, T.; Schmidt, F.; Jullien, L. Angew. Chem., Int. Ed. 2015, 54, 7492.

(26) Wang, Q.; Franz, K. J. Acc. Chem. Res. 2016, 49, 2468.

(27) Shamis, M.; Lode, H. N.; Shabat, D. J. Am. Chem. Soc. 2004, 126, 1726.

(28) Shabat, D.; Amir, R. J.; Gopin, A.; Pessah, N.; Shamis, M. Chem. - Eur. J. 2004, 10, 2626.

(29) Srinivasarao, M.; Low, P. S. Chem. Rev. 2017, 117, 12133

(30) Hettiarachchi, S. U.; Prasai, B.; McCarley, R. L. J. Am. Chem. Soc. 2014, 136, 7575 .

(31) Gnaim, S.; Shabat, D. Acc. Chem. Res. 2014, 47, 2970.

(32) Bruins, J. J.; Albada, B.; van Delft, F. Chem. - Eur. J. 2018, 24, 4749 .

(33) Genz, M.; Köhler, V.; Krauss, M.; Singer, D.; Hoffmann, R.; Ward, T. R.; Sträter, N. ChemCatChem 2014, 6, 736.

(34) Reetz, M. T.; Peyralans, J. J.-P.; Maichele, A.; Fu, Y.; Maywald, M. Chem. Commun. 2006, 4318.

(35) Chevalley, A.; Salmain, M. Chem. Commun. 2012, 48, 11984.

(36) Haquette, P.; Salmain, M.; Svedlunq, K.; Martel, A.; Rudolf, B.; Zakrzewski, J.; Cordier, S.; Roisnel, T.; Fosse, C.; Jaouen, G. ChemBioChem 2007, 8, 224.

(37) Cherrier, M. V.; Engilberge, S.; Amara, P.; Chevalley, A.; Salmain, M.; Fontecilla-Camps, J. C. Eur. J. Inorg. Chem. 2013, 3596.

(38) Pellizzoni, M.; Facchetti, G.; Gandolfi, R.; Fusè, M.; Contini, A.; Rimoldi, I. ChemCatChem 2016, 8, 1665. 
(39) Dürrenberger, M.; Heinisch, T.; Wilson, Y. M.; Rossel, T.; Nogueira, E.; Knörr, L.; Mutschler, A.; Kersten, K.; Zimbron, M. J.; Pierron, J.; Schirmer, T.; Ward, T. R. Angew. Chem., Int. Ed. 2011, 50, 3026 .

(40) Creus, M.; Pordea, A.; Rossel, T.; Sardo, A.; Letondor, C.; Ivanova, A.; LeTrong, I.; Stenkamp, R. E.; Ward, T. R. Angew. Chem., Int. Ed. 2008, 47, 1400.

(41) Pellizzoni, M. M.; Schwizer, F.; Wood, C. W.; Sabatino, V.; Cotelle, Y.; Matile, S.; Woolfson, D. N.; Ward, T. R. ACS Catal. 2018, 8, 1476.

(42) Pordea, A.; Creus, M.; Panek, J.; Duboc, C.; Mathis, D.; Novic, M.; Ward, T. R. J. Am. Chem. Soc. 2008, 130, 8085.

(43) Ward, T. R. Acc. Chem. Res. 2011, 44, 47.

(44) Heinisch, T.; Ward, T. R. Acc. Chem. Res. 2016, 49, 1711.

(45) Eiben, C. B.; Siegel, J. B.; Bale, J. B.; Cooper, S.; Khatib, F.; Shen, B. W.; Players, F.; Stoddard, B. L.; Popovic, Z.; Baker, D. Nat. Biotechnol. 2012, 30, 190.

(46) Robles, V. M.; Dürrenberger, M.; Heinisch, T.; Lledós, A.; Schirmer, T.; Ward, T. R.; Maréchal, J. D. J. Am. Chem. Soc. 2014, 136, 15676
(47) Jeschek, M.; Reuter, R.; Heinisch, T.; Trindler, C.; Klehr, J.; Panke, S.; Ward, T. R. Nature 2016, 537, 661.

(48) Jeschek, M.; Panke, S.; Ward, T. R. Methods Enzymol. 2016, 580, 539 .

(49) Bennett, B. D.; Kimball, E. H.; Gao, M.; Osterhout, R.; Van Dien, S. J.; Rabinowitz, J. D. Nat. Chem. Biol. 2009, 5, 593.

(50) Chen, F.; Romero-Canelón, I.; Soldevila-Barreda, J. J.; Song, J.; Coverdale, J. P. C.; Clarkson, G. J.; Kasparkova, J.; Habtemariam, A.; Wills, M.; Brabec, V.; Sadler, P. J. Organometallics 2018, 37, 1555.

(51) Kachur, A. V; Koch, C. J.; Biaglow, J. E. Free Radic. Res. 1998, $28,259$.

(52) Ngamchuea, K.; Batchelor-McAuley, C.; Compton, R. G. Chem. Eur. J. 2016, 22, 15937.

(53) Schwizer, F.; Köhler, V.; Dürrenberger, M.; Knörr, L.; Ward, T. R. ACS Catal. 2013, 3, 1752 . 
SYNOPSIS TOC (Word Style "SN_Synopsis_TOC"). If you are submitting your paper to a journal that requires a synopsis graphic and/or synopsis paragraph, see the Instructions for Authors on the journal's homepage for a description of what needs to be provided and for the size requirements of the artwork.

To format double-column figures, schemes, charts, and tables, use the following instructions:

Place the insertion point where you want to change the number of columns

From the Insert menu, choose Break

Under Sections, choose Continuous

Make sure the insertion point is in the new section. From the Format menu, choose Columns

In the Number of Columns box, type 1

Choose the OK button

Now your page is set up so that figures, schemes, charts, and tables can span two columns. These must appear at the top of the page. Be sure to add another section break after the table and change it back to two columns with a spacing of 0.33 in.

Table 1. Example of a Double-Column Table

\begin{tabular}{|l|l|l|l|l|l|l|l|}
\hline Column 1 & Column 2 & Column 3 & Column 4 & Column 5 & Column 6 & Column 7 & Column 8 \\
\hline & & & & & & & \\
\hline
\end{tabular}

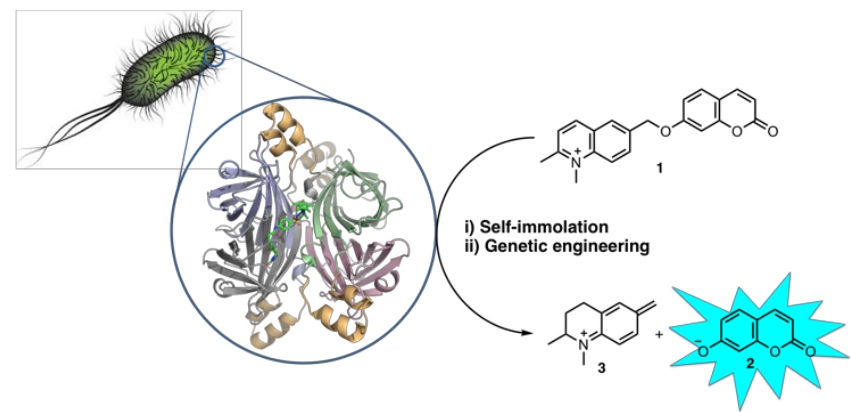

